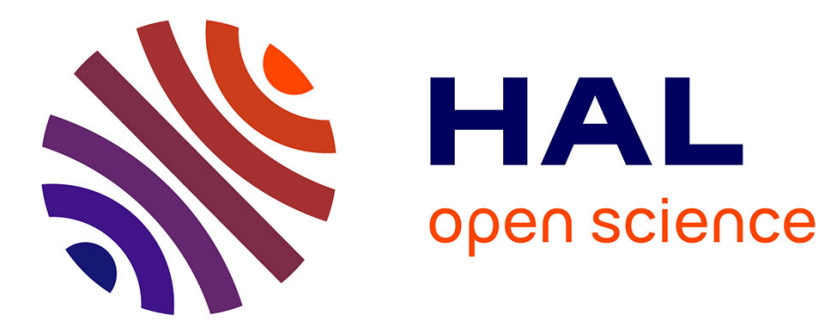

\title{
Slutsky's 1915 Article: How It Came to Be Found and Interpreted
}

John Somerset Chipman, Jean-Sébastien Lenfant

\section{To cite this version:}

John Somerset Chipman, Jean-Sébastien Lenfant. Slutsky's 1915 Article: How It Came to Be Found and Interpreted. 2001. hal-01771851

\section{HAL Id: hal-01771851 \\ https://hal.science/hal-01771851}

Preprint submitted on 30 Jul 2018

HAL is a multi-disciplinary open access archive for the deposit and dissemination of scientific research documents, whether they are published or not. The documents may come from teaching and research institutions in France or abroad, or from public or private research centers.
L'archive ouverte pluridisciplinaire HAL, est destinée au dépôt et à la diffusion de documents scientifiques de niveau recherche, publiés ou non, émanant des établissements d'enseignement et de recherche français ou étrangers, des laboratoires publics ou privés.

\section{(1)(1) $\$(0)$}

Distributed under a Creative Commons Attribution - NonCommercial - ShareAlikel 4.0 


\section{Slutsky's 1915 article: \\ How it Came to be Found and Interpreted}

This document is the penultimate version of a research article that has been published in the journal History of Political Economy in 2002. It departs from the published version on many points (notably footnotes and Appendix).

To quote the final published version:

Chipman, John S. and Jean-Sébastien Lenfant. 2002. Slutsky's 1915 article: How it Came to be Found and Interpreted. History of Political Economy, 34(3): 553-597. 


\title{
Slutsky's 1915 Article: How It Came to be Found and Interpreted
}

\author{
John S. Chipman ${ }^{\dagger}$ Jean-Sébastien Lenfant ${ }^{\ddagger}$
}

August 16, 1999

\begin{abstract}
It is well known that Slutsky's 1915 article "Sulla teoria del bilancio del consumatore" passed unnoticed and had to be rediscovered in the early nineteen thirties. The present article provides an account of what can be learned mainly from publicly available information of the relations among the main protagonists who participated in its rehabilitation (Dominedò, Schultz, Hicks, and Allen). In the first part, it is shown that the protagonists themselves were somewhat vague when they evoked the circumstances of their discovery of Slutsky's article, although it is reasonable to suppose that it was first re-discovered by Dominedò and that it came to be known soon afterwards by Schultz and Hicks. In the second part, the authors provide a rationale for this late and obscure recognition. It is shown that the protagonists did not share the same interpretation of Slutsky's paper, and that it was at the core of a methodological dispute between Schultz and Allen. While Schultz praised Slutsky's paper for providing a useful definition of complementarity, Allen stressed that Slutsky did not account for the non-integrable case.
\end{abstract}

* We are most grateful to Paul Samuelson and Milton Friedman for their comments on earlier drafts, as well as to Axel Leijonhufvud, Harald Hagemann, and Thomas Marschak for their cooperation. During preparation of the final draft of this paper, a paper by Weber (1999a) appeared covering some of the ground covered here.

${ }^{\dagger}$ Correspondence may be addressed to Prof. John S. Chipman, University of Minnesota, Department of Economics, 1035 Management and Economics, 271 19th Ave South, Minneapolis MN 55455, e-mail: jchipman@econ.umn.edu.

${ }^{\ddagger}$ Correspondence may be addressed to Jean-Sébastien Lenfant, G.R.E.S.E., Université de Paris 1, Maison des Sciences Economiques, 106-112 Bd de l'Hôpital, 75647 Paris Cedex 13, e-mail: lenfant@univ-paris1.fr. 


\section{Introduction}

In 1915 the Russian statistician and economist Eugen Slutsky sent off from Kiev an article to the Giornale degli Economisti that was translated and published in the July issue of that journal: "Sulla teoria del bilancio del consumatore". This article passed unnoticed. As is now well known, Slutsky's article is one of the most famous examples of those neglected and ignored works whose originality and importance is recognized only after similar results have been obtained by others. ${ }^{1}$ Many causes can account for such an oblivion. As Allen (1936) puts it:

It is interesting to note the existence of a long time-lag between the publication of a highly mathematical theory, such as those of Johnson and Slutsky, and the general recognition of the main results achieved in the theory. When it is remembered in addition, that Slutsky's article appeared in a journal of a country actively preparing for war, it cannot be considered as surprising that the work has remained completely unknown to Englishspeaking economists. (Allen 1936, 120)

Indeed, the fact that Slutsky's paper was published in an Italian journal may appear as the most natural explanation for passing unnoticed. As Hicks later stated:

How Slutsky, a Russian, came to publish his paper in an Italian journal does not seem to be known; neither in Italy, nor in Russia, nor anywhere else, did it make any impact. It had to be rediscovered after our [Hicks and Allen (1934)] work had come out. (Hicks 1981, 3)

Actually, that Slutsky published his paper in the Giornale degli Economisti is not at all surprising in view of the fact that, as Slutsky himself pointed out, he was completing the work of Pareto on utility and demand which was published in that very journal (1892-1893). ${ }^{2}$ Noteworthily, he commented on the fundamental equation of value in the following way:

\footnotetext{
${ }^{1}$ Although it is the best known oversight, its discovery lag is not the longest. Antonelli's 1886 paper was to wait until 1943 to be rediscovered by Wold (1943-44) (see Chipman, 1971, 321).

2 Actually, Pareto had come most of the way in deriving the Slutsky equation in October 1893 (Pareto 1893, 304-6), in particular to Slutsky's equations [43] and [44] (1915, 12), involving a term in the quantity of the commodity whose price is varied (identified by Slutsky as the income term), and another involving the marginal utility of income (identified by Slutsky as the substitution term). For details, see Chipman (1976, 72-4). The August 1892 article referred to by Slutsky dealt with the special case of additively separable utility, but employed the same method.
} 
The formulas in the text were deduced by Pareto, and published in this Giornale, August 1892 (see also the Manuel d'économie politique, 1909, p. 581). The differences in notation and form between our formulas and Pareto's are so unimportant that they may be considered identical. (Slutsky $1915,12 n)$

The most widely cited tribute to Slutsky's article was that of Allen (1936). ${ }^{3}$ But it is well established that Allen was not in fact the first author to mention it. As far as we are able to ascertain on the basis of published information, the discovery and full appreciation of Slutsky's article was made first by Valentino Dominedò, and subsequently - and independently of each other (but possibly not of Dominedò) - by Henry Schultz, and by Hicks and Allen. Although it is not possible to dispel the obscure circumstances of those separate rediscoveries, it is quite possible to suggest some. ${ }^{4}$ In the first part, we shall provide a brief commentary on each of those three separate rediscoveries, focussing mainly on factual information. In view also of the rather evasive information from the protagonists themselves, it may be interesting to go a bit further and comment on the methodological context of the discovery in the theory of utility and demand. Thus, in the second part, we shall focus on the way Slutsky's paper was interpreted by the protagonists themselves. By comparing Schultz's and Allen's interpretations of Slutsky's contribution, it is shown that Slutsky's paper in the thirties soon became the subject of a theoretical controversy.

\section{Three separate rediscoveries}

Three distinctive "teams" of protagonists can be identified in this story. The last two came across Slutsky's article (1915) quite independently of each other, if not of the first. We shall take things up, as far as possible, in chronological order.

\footnotetext{
${ }^{3}$ Allen (1950) later came back to this subject.

${ }^{4}$ It is possible that some of the uncertainties that still exist can be cleared up by scholars who have access to the unpublished papers of Hicks, Allen, Schultz, and others. For instance, Hands and Mirowski (1998) provide some material from the Harold Hotelling Correspondence (hereafter HHC) relating to Slutsky's article. Unfortunately we have been unable to gain access to Hicks's papers deposited in Brasenose College, Oxford.
} 


\section{The Ricci-Dominedò team}

The first appreciation of Slutsky's work in the economic literature was Dominedò's long 1933 paper on the theory of demand. Dominedò $(1933,789-805)$ devoted the last pages of this article to Slutsky's mathematical and theoretical exposition, "a writing of remarkable value, although of difficult reading" (Dominedò, 1933, $790 \mathrm{n}$ ) and, as we shall see later, he was certainly the first author to have grasped the importance of Slutsky's paper. But Dominedò does not seem astonished that it should have passed unnoticed until that time. There remains the question of how Dominedò came across Slutsky's article. One of the authors has checked all the post-1915 works referred to in Dominedò (1933), and in only one of them has he found a reference to Slutsky (1915): that of Ricci (1932a). This is a first irony in this story, knowing the fact that Ricci embodies the purest Marshallian, cardinalist and hedonist tradition in the Italian academic world of that period. In an early article, Ricci (1904) had considered a case in which a person's utility function was additively separable in the quantities. Instead of assuming diminishing (as well as positive) marginal utility for all commodities, Ricci allowed one of the commodities to have at first increasing and subsequently decreasing marginal utility. He then showed (Ricci, 1904, 135) that provided a certain inequality was fulfilled, demand for this commodity in an interval of increasing marginal utility would be an increasing function of its price. Slutsky $(1915,18)$ discussed Ricci's result, and showed that Ricci's inequality was precisely the violation of the second-order condition for a constrained maximum of utility (the so-called "stability condition"). ${ }^{5}$ Ricci returned to this question in his 1932 article cited by Dominedò, and conceded Slutsky's criticism; he also provided a more detailed explanation of the fallacy that Slutsky had exposed. ${ }^{6}$ Thus, we may ask the question: if Ricci had not committed his error in 1904, allowing Slutsky to expose

\footnotetext{
${ }^{5}$ Recently, Samuelson $(1998,1378)$ reported an "inexplicable error" in the Foundations that had been communicated to him, "alleging that when one of many independent utilities involved a permissible rising marginal utility, then that good could have negative income elasticity." This apparently refers to an off-the-cuff remark in Samuelson $(1947,186)$, as against Ricci's entire article (1904) on the subject.

${ }^{6}$ Ricci subsequently $(1935,183)$ returned once again to the analysis of the case of increasing marginal utility, referring to Ricci (1932a) but not to Slutsky (1915).
} 
it in his 1915 article, and if Ricci had not recanted in 1932, would we still not know about Slutsky's contribution?

Precisely when Ricci came across Slutsky's paper is not known. Although Ricci published a paper in the same July 1915 issue of the Giornale degli Economisti (Ricci, 1915), years later Ricci (1924, 419 and 425) still referred favorably to his earlier 1904 article, without giving any indication that he had yet come across Slutsky's article. It is also to be noted that in another 1932 article in the Journal of Political Economy (Ricci, 1932b), he does not mention Slutsky; nor does he in his 1933 article on the demand for substitutes (Ricci, 1933). Thus, we must date Ricci's discovery of Slutsky's article as having occurred during the period 19251931, probably closer to the later date. Although Ricci is probably the fist economist to mention Slutsky's article in a published paper, he certainly had no conception of its importance, nor did he participate in its rehabilitation.

\section{The Schultz-Friedman team}

The first published recognition of Slutsky's important paper in America may be found in Schultz's 1935 article: "Interrelations of demand, price, and income". Actually, it is known that Milton Friedman, a young research assistant to Schultz at Chicago, participated actively in this article and in the subsequent 1938 book. ${ }^{7}$ To that extent, Friedman and Schultz share in the rehabilitation of Slutsky's article. $^{8}$ Indeed, Schultz's 1935 paper contains a detailed analysis of Slutsky's article as well as a comparison with that of Hicks and Allen (1934). In this paper, Schultz tackles the issue of determining the reaction of consumers to a change in their income and in the price of a commodity:

The solution of this problem was first given by Pareto in 1892, but was simplified, extended, and put in more elegant form by Professor Eugen Slutsky, the Russian statistician and economist, in a remarkable paper in 1915. (Schultz 1935, 439-440)

\footnotetext{
${ }^{7}$ To a certain extent, Schultz shared the paternity of the 1935 article in the following terms: "I am profoundly grateful to Mr. Milton Friedman for invaluable assistance in the theoretical and statistical investigations which underlie this study" (Schultz 1935, 433). See also Schultz (1938, xi), and footnote 19 below.
} 
Neither in this paper, nor in the subsequent canonical work The Theory and Measurement of Demand, did Schultz specify in what circumstances, and precisely when, he came across Slutsky's 1915 article. At one place, he says that:

The importance of this paper appears to have been overlooked until 1933, when it was discovered by Valentino Dominedò, of the University of Bocconi, by Mr. J. R. Hicks, and by myself. (Schultz 1938, 38n.; italics added)

While at another place, he says:

Hicks and Allen derived their results quite independently of Slutsky's paper . . . which was discovered by Dr. Hicks and myself in 1934. (Schultz, 1938, 620; italics added)

On this question, we must be content with conjectures. Henry Schultz, who had acquired a wide familiarity with European works, spent the year 1933-1934 in Europe (Schultz 1938, xi), where he was able to make himself acquainted with the work of Hicks, Allen, and others on the foundations of demand theory. Thus, it is likely that Slutsky's paper was brought to his attention during his European tour (Hands and Mirowski 1998, 361), at about the time when Dominedò's 1933 article was published. The 1933 Dominedò article to which Schultz referred contains references to earlier writings by Schultz $(1928,1933),{ }^{9}$ and Schultz's 1938 work shows great familiarity with the Italian literature and provides evidence of his extensive correspondence with Italian economists; so it is reasonable to conjecture that Dominedò sent (or even handed) an offprint of his article to Schultz. Schultz, while browsing through the Giornale degli Economisti in the University of Chicago library may even have come across Slutsky's article himself.

Nevertheless, some of Schultz's observations are puzzling. Is it not curious that Schultz, who was a careful scholar, makes no mention of Allen as one of the discoverers? Is it not also puzzling that, if we are to take the first of the above

\footnotetext{
${ }^{8}$ As early as May 1935, Schultz had prepared an English translation of Slutsky's paper, which he sent to Hotelling (Hands and Mirowski 1998, 361).

9 In contrast, while Dominedò referred to Johnson (1913), he did not refer to Allen's earlier work (1932).
} 
passages from Schultz (1938) literally, Hicks would also have discovered Slutsky's article in 1933, before the publication of the Hicks-Allen article! ${ }^{10}$

\section{The Hicks-Allen team}

Hicks and Allen (1934, 209-210) had obtained, independently of Slutsky (1915), a decomposition of the elasticity of demand for a good into a term involving the income elasticity of demand and an elasticity of complementarity (the well-known income and price effects). Hicks (1937, 13-14) subsequently (giving credit to Slutsky but not providing any reference) showed how this was related to Slutsky's equation, which he described as the "fundamental equation of the theory of value" (Hicks, 1937, 13). The first explicit discussion of Slutsky's article by the HicksAllen team was that of Allen (1936), who recognized its importance in the following words:

In the [1934] article, much use was made of the ideas of the mathematical work of Johnson, but we thought that some of the results attained, as apart from the method of approach, were entirely original. More recently, however, our attention has been drawn to an important article by Professor Slutsky, of Charkov University .... ${ }^{11}$ (Allen 1936, 120)

Who was to draw their attention to this article? We do not know. Allen (1950, 210) is not very explicit: "Independently [of Schultz], though a little later [than 1934], Hicks and I were led back to Slutsky's original work by various references to it." What are those "various references"? We do not know; but we may conjecture that they were Dominedò (1933) and Ricci (1932a). At least we may note that Allen concedes Schultz's priority on that matter, and that he does not mention Dominedò: "It appears that Schultz discovered Slutsky's Giornale article rather earlier than, but quite independently of, Hicks and myself" (Allen 1936, 120n).

As a testimony to Slutsky's misfortune in publishing his article in a wartime Italian journal, Allen $(1950,210)$ states that "even Schultz did not discover

\footnotetext{
1934.

${ }^{10}$ Part I of Hicks and Allen (1934) was published in February 1934; Part II appeared in May

${ }^{11}$ Slutsky taught at the School of Commerce in Kiev, not Kharkov. Apparently Allen confused these two Ukrainian cities.
} 
Slutsky's article until around 1934." Certainly Allen takes Schultz's familiarity with Italian economists for granted, especially with the Paretian tradition. ${ }^{12}$ But the same thing could be said of Hicks who, it has been recounted, could speak and write Italian, and knew his Italian colleagues very well. ${ }^{13}$ In his 1937 contribution and in Value and Capital as well, he is quite vague on that subject. ${ }^{14}$ Nevertheless, his tribute to the Russian statistician and economist is more profuse than Allen's:

Credit must be paid to the Russian economist Eugen Slutsky for approaching the research in a fruitful way for the first time. . . Slutsky's work almost escaped notice. I did not know about it when I began my own research; R. G. D. Allen and myself discovered similar results without Slutsky's assistance. (Hicks 1937, 4-5)

More noticeable also is the fact that Hicks (1939) does not hesitate to recognize Slutsky's importance in the theory of utility and demand. He also sheds some light of his own on the chronology of the discovery:

\footnotetext{
${ }^{12}$ See for example Schultz $(1931 ; 1938)$.

${ }^{13}$ According to Legris $(1995,109)$, "Hicks went to Italian universities every year." Legris does not provide any source for his information; however, we have Hicks's own testimony (1979, 196;1984, 282) that in 1926, his first year as lecturer at the London School of Economics, Hugh Dalton had remarked to him: "you read Italian; you ought to read Pareto," and that this had started him off reading Pareto's Manuale (1906a). Hicks went on to remark: "My Italian had begun by stumbling through Dante, while I was still at school; I had gone on to read fairly widely in Italian literature. But it was not until 1933, after I had published Theory of Wages, that I made my first contact with Italian economists, visiting, in Turin, Einaudi and Cabiati, del Vecchio at Bologna and Marco Fanno at Padua." It is intriguing to speculate whether he might have learned of Slutsky's article during that visit, say by meeting Dominedò (who was, however, at Milan; Ricci had been at Bologna, but was then in Cairo). Hicks also mentioned (1979, 198n; 1984, 284n) that Claude Guillebaud "was the only other British economist I have known who knew the last canto of the Paradiso by heart." Finally, we have his statement (1979, 204; 1984, 290): "I have explained the importance of my knowledge of Italian (which is still, I fear, little more than a reading knowledge) in the beginnings of my economics. It has been a great thing for me that I have been able to use it in the contacts with Italian economists which I have been able to develop during the last twenty years" (1960-1979). Axel Leijonhufvud has confirmed for us (in a communication of 4 March 1999) that "John Hicks could get along in Italian after a fashion . . . . I believe his and Ursula's practice of coming to Italy every year started quite some time after the war."

That Hicks was not unacquainted with the Giornale degli Economisti is proved by the fact that in an early article (Hicks 1933, 455) he quoted a passage from Fanno (1931) in that journal - a passage that was, however, omitted from the English translation (Hicks 1980, 534n). It is curious that Hicks apparently never acknowledged Fanno's priority in introducing the concept of the marginal rate of substitution $R y x$ between goods $X$ and $Y$ as a function of their quantities $x$ and $y$ (defined only for homogeneous utility functions, however), and the principle of the diminishing marginal rate of substitution (Fanno 1926, 361-2 and 1929, 60). Fanno did not, by the way, refer to Slutsky (1915).

${ }^{14}$ Hicks $(1981,3)$ does not provide more information
} 
The theory to be set out in this chapter and the two following is essentially Slutsky's; although the exposition is modified by the fact that I never saw Slutsky's work until my own was very far advanced, and some time after the substance of these chapters had been published in Economica by R. G. D. Allen and myself. Slutsky's work is highly mathematical, and he does not give much discussion about the significance of his theory. These things (and the date of its publication) perhaps explain why it remained for so long without influence, and had to be rediscovered. (Hicks 1939, 19)

As Hicks adroitly suggests, it is quite probable that Slutsky's article had been read by some economists of the period, but that its originality had not been noticed. We are then led to ask the following question: Why was Slutsky's paper rediscovered? With a view to answering the question, it is useful to set out the theoretical context in which Slutsky's article was discovered and received attention. Thus, how it came to be interpreted will shed some light on how it came to attract attention.

\section{The theoretical context of Slutsky's rehabilitation}

The theoretical context of Slutsky's rehabilitation may be characterized in roughly the following way. On the one hand, mathematical economists of that period tried to pursue the analysis of demand along the lines of the Paretian theory of the equilibrium of the individual consumer. To that extent, it is not surprising that Slutsky's article was presented as a culmination of the Paretian program. The "Slutsky equation" was thus presented as the clearest expression of this decomposition into a price effect and an income effect. Furthermore, Slutsky's article was driven by the idea of testing economic relations empirically; this also can be traced to Pareto's methodological principles. To that extent, the most important result of Slutsky's paper is not the Slutsky equation, but the symmetry relation, which was the most general empirical restriction on individual demand functions. As regards this methodological aim, it is not surprising that Slutsky's paper attracted statistical as well as mathematical economists. In this section, we shall suggest that Slutsky's results were not interpreted in the same way by the main protagonists of this story. 


\section{Slutsky's interpretation of his results}

Let's come back to Slutsky's equations expressing the variation in the demand of a good in reaction to a variation of the price of another good. The fundamental equation of value theory can be written as follows (adopting Slutsky's notation):

$$
\frac{\partial x_{i}}{\partial p_{j}}=u^{\prime} \frac{M_{i j}}{M}-x_{j} \frac{\partial x_{i}}{\partial s},
$$

where $x_{i}$ is the quantity demanded of commodity $i, p_{j}$ is the price of commodity $j$, and $s$ is income, while $u^{\prime}$ is the marginal utility of income, $M$ is the determinant of the matrix of second-order partial derivatives $u_{i j}$ of the utility function bordered by the prices, and $M_{i j}$ is the minor of this matrix corresponding to the element $u_{i j}$.

From basic properties of determinants Slutsky derived the following equalities: ${ }^{15}$

$$
k_{i j}=u^{\prime} \frac{M_{i j}}{M}=\frac{\partial x_{j}}{\partial p_{i}}+x_{i} \frac{\partial x_{j}}{\partial s}=\frac{\partial x_{i}}{\partial p_{j}}+x_{j} \frac{\partial x_{i}}{\partial s}=u^{\prime} \frac{M_{j i}}{M}=k_{j i}
$$

$k_{i j}$ can be interpreted as the change, $d x_{j}$, in the quantity demanded that would result if the price change, $d p_{i}$, were accompanied by a compensating adjustment in money income such as to "make possible the purchase of the same quantities of all the goods that had formerly been bought" (Slutsky 1915, 14). In Slutsky's words, $k_{i j}$ is the "residual variability" of the $j$ th good for a "compensated variation" of the price $p_{i}$. The equality $k_{i j}=k_{j i}$ (equation [55] in Slutsky's paper) is called the law of reversibility (hereafter the "Slutsky symmetry condition") and is expressed in the following way:

The residual variability of the $j^{\text {th }}$ good in the case of a compensated variation of the price $p_{i}$ is equal to the residual variability of the $i^{\text {th }}$ good in the case of a compensated variation of the price $p_{j}$. (Slutsky 1915, 15; italics in original)

\footnotetext{
${ }^{15}$ McKenzie (1957) subsequently provided a simplified derivation of (2), using duality.
} 
In Slutsky's view, the symmetry condition is a quantitative, measurable relationship:

Equation [55] belongs to the previously mentioned category of quantitatively defined relations between observable quantities. Empirical confirmation is highly desirable, inasmuch as it would demonstrate the correspondence to the truth, or at least the plausibility, of the hypothesis that the increments of utility do not depend upon the mode of variation. (Slutsky $1915,15)$

Moreover, Slutsky comes to the conclusion that the determination of the second derivatives of the utility function on the basis of empirical data is a vain effort. This conclusion has tremendous, and to Slutsky's eye awkward, consequences on the relation between psychology and economics:

The conclusion is not satisfactory; because, even though attaching great importance to the absolute logical independence of the methods of economic science from those of psychology, we would not ignore the existence of a very complicated interdependence between the facts studied by those two sciences. (Slutsky 1915, 24; italics in original)

Here we arrive at Slutsky's final conclusion on the distinction between complementary and competitive goods. Slutsky challenges the "traditional" definition of substitutes and complements according to the sign of the second cross partial derivatives of the utility function: ${ }^{16}$

this whole edifice falls if one remains loyal to the formal definition of utility, for it is impossible to deduce from the facts of behavior the character (that is, the sign) of the second derivatives of utility. (Slutsky 1915, 25)

\footnotetext{
${ }^{16}$ This definition was first proposed by Auspitz and Lieben (1889, 482; 1914, 318-319), and was later adopted by Fisher $(1892,65)$. Edgeworth $(1897,20-21 \mathrm{n} ; 1925,117 \mathrm{n})$ mentions Auspitz and Lieben in the course of introducing the definition, but does not credit them with it, while subsequently he appears to claim novelty for it (Edgeworth 1915, 49; 1925, 464): ". . the simpler definition which was proposed some years ago", referring to his 1897 paper. Pareto (1906a, Ch. IV, 263-5 and Appendix, §11-15, 503-9; 1909, Ch. IV, 264-5, and Appendix, §46, 575 and $\$ 124$, 654) introduced the Auspitz-Lieben definition of complementarity without crediting Auspitz and Lieben. While he may have been acquainted with this definition through Edgeworth (Pareto 1909, $\S 69,595 \mathrm{n}$ ), since there is no reference to Edgeworth's 1897 paper in Pareto (1906a), he probably considered it original, although he had earlier read and reviewed Auspitz and Lieben's book. As for Slutsky, since he referred extensively to Pareto's Manuel (1909), it is reasonable to infer that he got the Auspitz-Lieben definition from the Manuel and not from Auspitz and Lieben or Edgeworth.
} 
In short, Slutsky wishes to generalize the principle of ordinal utility, and to infer from it the most general empirical restrictions on individual demand behavior. For all that, he clings to the idea that the second cross derivatives of the utility function should have intuitive properties. From this, we are in a position to comment on Slutsky's discoverers. Indeed, it should to be noticed that all the protagonists of this story will focus on this aspect of Slutsky's article.

\section{Schultz's operationalist approach}

Let us begin with Schultz. In the early thirties, Schultz is engaged with Hotelling in a search for theoretical restrictions on statistical demand functions, based on utility analysis, with a view to improving the analysis of market interdependencies. Hotelling (1932) had derived symmetry conditions on demand behavior through maximization of entrepreneurial utility functions. ${ }^{17}$ Schultz (1933) had found similar restrictions on consumer demand functions through a constrained maximization of utility, under the hypothesis of "constant" (independent of prices) marginal utility of money. This condition (3) is equivalent to the Slutsky symmetry conditions when income effects are neglected: ${ }^{18}$

$$
\frac{\partial x_{i}}{\partial p_{j}}=\frac{\partial x_{j}}{\partial p_{i}}
$$

But Schultz's (1933) tests of those conditions for agricultural products were disappointing. Something else is needed. Slutsky's paper is arriving in the nick of

\footnotetext{
17 An entrepreneurial demand function (introduced by Court, 1941) is derived from profitmaximization by a firm not subject to a budgetary constraint: $u\left(x_{1}, x_{2}, \ldots, x_{n}\right)-p_{1} x_{1}-p_{2} x_{2}-\ldots-p_{n} x_{n}$, where $u(\cdot)$ denotes the firm's revenue function (Hotelling 1932, 590).

18 Hotelling's "integrability conditions" can also be derived under certain preference hypotheses. Chipman and Moore $(1976,107)$ showed that under utility maximization, (3) is implied by homotheticity of preferences (see also Samuelson 1942, 81n). Recently, Hurwicz (1998, 407-9) showed that (3) in turn implies homotheticity. Samuelson (1950, 357n) showed that if, instead, preferences have the parallel form represented by the quasi-linear utility function $u\left(x_{1}, x_{2}, \ldots, x_{n}\right)=x_{1}+v\left(x_{2}, \ldots, x_{n}\right)$, so that commodity 1 has constant marginal utility $=1$, then maximization of $u$ subject to the budget constraint $1 x_{1}+p_{2} x_{2}+\ldots+p_{n} x_{n}=s$ is equivalent to the unconstrained maximization of$$
v\left(x_{2}, \ldots, x_{n}\right)-p_{2} x_{2}-p_{3} x_{3}-\ldots-p_{n} x_{n}+s
$$

(see also the discussion in Hurwicz 1998, 409). It should be noted that Hotelling (1935) subsequently dealt with the case of budget-constrained consumer demand functions, expressed as indirect demand functions (prices as functions of income and quantities), but did not consider the corresponding "integrability conditions." See also Hands (1993) for an epistemological appraisal.
} 
time as a solution to those difficulties. Moreover, it was now necessary to implement a new interpretation and a new definition of complementary and competitive goods in consumption. As regards this, Slutsky's equation was to provide the solution. Schultz was well aware that (3) rested on weak foundations, and Slutsky's equation was then to play a central role both in providing general conditions on individuals' market behavior and new definitions of complementarity:

In terms of the Slutsky conditions, two commodities may be defined as completing or competing, according as the direct effect [residual variability] of an increase in the price of one of the goods is to bring about a decrease or an increase in the demand for the other. (Schultz 1935, 481)

Otherwise stated, two goods will be completing, independent or competing, according as $k_{i j}$ is negative, zero, or positive. This definition not only is free from any measurable utility function, but also "may be obtained by observing the individuals' market behavior" (Schultz 1935, 459). Here, we may find the influence of Dominedo $(1933,804-805)$ who was the first to provide this definition of complementarity on the basis of the Slutsky equation. Given also that Friedman was trying to provide a new definition of substitutes and complements at the time,${ }^{19}$ it is probable that he and Schultz did not absorb the full implications of Slutsky's paper independently of Dominedò. ${ }^{20}$ In any case, Schultz (1935) developed the analysis of statistical demand much more on Slutsky's basis than on Hicks and Allen's. Especially on substitutes and complements, Schultz (1935, 447) emphasizes that Hicks and Allen (1934) do not provide any explicit definition of complementarity for the more-than-three-goods case. In Schultz's

\footnotetext{
${ }^{19}$ Friedman's unpublished paper (1934) is copiously cited in Schultz $(1938,614-619)$. In a letter to the first author dated 19 January 1999, Friedman wrote: “. . I was studying with Harold Hotelling at Columbia, having been recommended to Hotelling by Schultz, when I wrote the paper which is referred to in Schultz's book as dated January 1934. . . . I started working for Schultz in October 1934. As I recall it, Schultz had written a first draft of chapters 18 and 19, and . . I thoroughly rewrote them, undoubtedly adding new material, such as reference to my own paper, in the process. However, I have no recollection of knowing anything about how or where or under what circumstances Schultz came across Slutsky's article. In my earlier paper, I have footnotes to Lenoir, Fisher, Pareto, Edgeworth, etc., but none to Slutsky, which almost surely means that Hotelling was unaware of Slutsky's article in 1933." (See footnote 7 above). Friedman's definitions of complements and substitutes are in the spirit of Johnson and Allen, but developed quite independently.
} 
view (Schultz 1935, 479n), Slutsky's compensated variations are even superior to Hicks and Allen's elasticities of complementarity. ${ }^{21}$ Otherwise stated, Schultz and Friedman consider that Slutsky (1915) goes beyond Hicks and Allen (1934). In a letter dated 6 March 1935, Friedman reported on their common enthusiasm to Hotelling:

[Slutsky] clearly recognises the diffiulty presented by the non-measurability of utility and indeed presents a proof that it is impossible to obtain the second derivatives of the utility function from empirical data. His paper contains practically everything that is in the Hicks-Allen paper recently published and much more besides. (HHC, Box 1, Friedman to Hotelling, quoted in Hands and Mirowski 1998, 361)

Two months later, Schultz also wrote to Hotelling:

The paper is remarkable for completing Pareto's work on demand and supply and for giving the Hicks-Allen results in a simpler and more understandable form. (HHC, Box 1, 5/6/35, quoted in Hands and Mirowski,1998, 361)

Schultz emphasizes the new definition of complementarity, on the basis of the Slutsky equation. It is no longer necessary to have recourse to an introspective comparison. Instead, observation is all that is necessary for the new definition:

If we wish to know whether the individual considers two commodities as completing, independent, or competing, we must note his income, and observe whether a fall in the price of one of the goods, accompanied by a compensating variation in his income, will cause him to increase, maintain constant, or decrease his purchases of the other. . . [This] may be obtained by observing the individual's market behavior; whereas the answers called for by $\left[\partial^{2} u / \partial x_{i} \partial x_{j}\right]$ cannot be so obtained..$^{22}$ (Schultz, 1935, 462-3; italics in original)

\footnotetext{
${ }^{20}$ Although Schultz (1935) does not mention Dominedò (1933).

${ }^{21}$ Furthermore, Schultz also gives statistical evidence in favor of Slutsky's definition against Hicks and Allen's (Schultz, 1935, 479n). A comparison between the Hicks-Allen and SlutskyFriedman-Schultz definitions may be found in Schultz $(1935,447)$. See also Allen (1936) and Samuelson $(1974,1269)$.

${ }^{22}$ As will be observed below, however, complementarity according to the latter definition carries empirical implications not shared by complementarity according to the former definition.
} 
The fundamental point concerning Schultz's attitude towards Slutsky's improvement of the theory of demand is that it leads to operationally meaningful statements. As regards this, Schultz (1938) provides long quotations from Percy Bridgman's The Logic of Modern Physics, adopting his operationalist philosophy of science: ${ }^{23}$

As long as a concept remains nonoperational, it is vain to hope that it will yield to the quantitative approach. The restatement and extension of the earliest concept of demand into forms which have meaning in terms of operations . . . is the first step in the direction of the derivation of concrete, statistical laws of demand. (Schultz 1938, 12)

This laudatory attitude toward Slutsky's contribution, both from a methodological and theoretical point of view, stands in contrast with Allen's methodological criticism of Slutsky's paper. In contrast to Allen, Schultz was above all searching for testable theoretical relations among substitutes and complements, rather than for a measure of complementarity as such; and in this regard the Hotelling and Slutsky conditions

constitute a category of laws which is comparatively rare in the social sciences: they specify quantitatively definite relations which must exist between variables - if the theory is true. They thus enable us to test the extent of the agreement between theory and fact. (Schultz 1935, 480; italics in original)

Schultz was apparently alone among the writers of that period in recognizing the aggregation problem: that even if the Slutsky conditions (2) hold for each individual, they need not hold for an aggregate of individuals, and statistical verification necessarily deals with aggregates. Schultz also perceived $(1935,474-$ $5 n$ ) that a sufficient condition for aggregability was that "the partial derivatives of the quantity of each commodity with respect to income is [sic] the same for each

${ }^{23}$ See also Schultz (1931b, 650). To explore the exact relations between Bridgman's and Schultz's methodology is beyond the scope of this article. Suffice it to say that according to Bridgman $(1927,5)$ : "In general, we mean by a concept nothing more than a set of operations; the concept is synonymous with the corresponding set of operations." However, Schultz's use of the term "operational" (also Samuelson's, 1947) is much broader than this, consisting simply in the principle that scientific propositions should be capable of being tested empirically, perhaps indirectly as well as directly. On operationalism in economics, see Mirowksi (1998). 
individual" - a condition first noted by Antonelli (1886) and much later by Gorman (1953), Nataf (1953), and Theil (1954). ${ }^{24}$ He found that the Slutsky conditions were not verified in his fitting of linear demand functions to aggregate data (Schultz, 1935, 476), but that the same was true of the Hotelling conditions (3), even though the latter were aggregable. ${ }^{25}$

\section{Allen's methodological criticism: the integrability issue}

It is also remarkable that most of Allen's remarks on Slutsky deal with the theory of substitutes and complements. Allen (1936) focusses mainly on this topic:

It is now clear that many of our results were first given explicitly by Slutsky in this article and that, though the results were not interpreted in terms of the complementary and competitive relations between goods, yet his own use of them was essentially very similar to ours. (Allen 1936, 120)

As we have remarked, the Hicks-Allen (1934) decomposition similar to Slutsky's is expressed in term of elasticities. There is no fundamental distinction between one definition and the other, except that Slutsky expresses a compensated change in income explicitly, whereas Hicks and Allen do not. Also, Hicks and Allen employ the notion of elasticity of complementarity, whereas Schultz

\footnotetext{
${ }^{24} \mathrm{He}$ also specified as an alternative sufficient condition that "each individual consumes the same amount of a particular commodity and any increase in total income is distributed equally among the individuals" - a condition that is close to the correct condition that if all individuals have homothetic preferences and the distribution of income remains proportional, then the aggregate demand will satisfy the Slutsky conditions (cf. Chipman 1974). Only a year later, however, Schultz $(1936,617)$ apparently forgot these conditions when criticizing Allen and Bowley (1935) in the following terms: "Since individual indifference curves cannot be aggregated to form the indifference curve of the group except by postulating a utility function for the group, does not the statistical procedure of the authors come dangerously close to implying that utility is not only measurable but that the utilities of different persons are comparable?"

${ }^{25}$ As pointed out by Samuelson $(1974,1284)$, Schultz's econometric specification was marred by the assumption of affine demand functions, in violation of zero-degree homogeneity, among other defects. Recent, more sophisticated, tests carried out by Jorgenson and Lau (1977, 1979, 1986) have, however, also confirmed Schultz's conclusion, which is not too surprising in view of the results of Sonnenschein (1972, 1973), Mantel (1974), and Debreu (1974) (see also McFadden, Mas-Colell, and Richter, 1974), to the effect that any continuous function of n prices satisfying (1) homogeneity of degree $0,(2)$ boundedness from below, and (3) Walras's law (the properties that are preserved by aggregation of individual excess-demand functions) can be expressed as the aggregate of individual excess-demand functions of $\mathrm{n}$ rational consumers. Thus, severe assumptions regarding similarity of preferences are required in order to make the Pareto-SlutskyHicks-Samuelson theory of demand "operational" in the sense of containing empirically refutable propositions. On this see the interesting discussions by Diewert (1977) and Green and Moss (1994, 71).
} 
employs the concept of the elasticity of demand with respect to a compensated variation in price. But according to Allen (1936), this similarity between Slutsky's and his own results does not prevent Slutsky's paper from having some fundamental flaws. Indeed, Allen criticizes Slutsky's equation on the ground that it rests on weak theoretical foundations. His central point is that Slutsky does not account for the non-integrable case, although the results he obtains are completely independent of any measurable utility:

In any case, Slutsky's starting point is different from that of Hicks and myself. Our theory was constructed so as to be independent of the existence of an index of utility and it was only in a special case, the so-called "integrability case", that such an index was taken. This integrability case may be the most interesting and useful of all, but it remains a special case of a more general theory. Slutsky, on the other hand, assumes the special integrability case from the outset and his results are therefore, unnecessarily limited. This is, of course, perfectly realised by Slutsky himself. (Allen $1936,127)$

As a consequence, Allen (1936, 127) maintains that although "the results of Slutsky's analysis are ... unobjectionable, ... the method of attaining the results... is open to objection." Thus, Allen suggests that Hicks and Allen's (1934) approach is preferable, because it rests on the sole hypothesis of a diminishing marginal rate of substitution, and does not presuppose the existence of a utility function: "From the purely methodological point of view, this seems a development preferable to that of Slutsky" (Allen 1936, 127). ${ }^{26}$

Here we come to the fundamental point of Allen's argument. Although Allen is in accord with Slutsky's aim of providing statistical evidence for the symmetry conditions (Allen 1936, 125-7), he is more concerned with finding ways to measure complementarity and substitutability:

\footnotetext{
${ }^{26}$ It is to be noted that Allen's methodological objection to formula (2) was not settled at once. McKenzie (1957) claimed that it did not depend on the existence of a utility function (i.e., on integrability). However, Newman and Read (1958) argued that McKenzie's assumptions implied the existence of a utility function. Subsequently, Hurwicz and Uzawa (1971) showed that Slutsky symmetry and negative semi-definiteness implied integrability after all (if a Lipschitz condition is assumed).
} 
The advantage of our method of approach does not, however, lie only in the sphere of methodology. The very fact that we rejected the marginal utility concept in favour of the marginal rate of substitution concept lead [sic] to the introduction of the ideas of the elasticities of substitution and complementarity. (Allen 1936, 127-8)

From this, Allen infers that the elasticity of substitution and complementarity is a more general tool than Slutsky's residual variabilities. Otherwise stated, Hicks and Allen's (1934) definition of complementarity is said to have "much to recommend it as compared with Slutsky's rigidly Paretian approach by way of a utility function and marginal utilities" (Allen 1936, 128), since the elasticity of substitution between $i$ and $j$ need not be equal to that between $j$ and $i$. In the integrable case, the elasticity of substitution in Hicks and Allen (1934) is said to be proportional to Slutsky's residual variability $k_{i i}$ with sign changed (Allen 1936, $129) ;{ }^{27}$ and the elasticity of complementarity of the $i$ th with the $j$ th good is proportional to Slutsky's residual variability $k_{i j}$. On the basis of this and of the methodological remarks, Allen emphasizes that, in Slutsky's paper, "the complementary and competitive interpretation of the formulae remains implicit" (Allen 1936, 129), and that "Slutsky's law of reversibility holds only [in] this special [integrability] case and asserts the symmetry of the complementary or competitive relation between goods" (Allen, 1936, 129). ${ }^{28}$

${ }^{27}$ This is true only in the special two-commodity case. Hicks $(1937,17)$ showed that the elasticity of substitution $\sigma_{i j}$ - defined in Hicks $(1937,14)$ - satisfied the condition

$$
\sum_{j \neq i} k_{j} \sigma_{j i}=-k_{i} \sigma_{i i}>0,
$$

where Hicks's $k_{i}$ denotes the proportion of income devoted to commodity $i, p_{i} x_{i} / s$. For $n=2$ it follows that

$$
\sigma_{12}=-\left(p_{1} x_{1} / p_{2} x_{2}\right) \sigma_{11}
$$

$\sigma_{11}$ being proportional to Slutsky's $k_{11}$ (cf. Hicks 1937, 14; also Hicks 1970). However, Allen went on to explain this relation in terms of an $n$-commodity model.

${ }^{28}$ See also Hicks and Allen (1934, 72 and 202). It is worth commenting on the interesting fact that Hicks and Allen (1934) defined independence not by a zero elasticity of complementarity but in quite a different way. Hicks $(1934,74-75)$ defined the pair $Y Z$ of goods to be "independent" if the marginal rate of substitution between them depends on the quantities of $Y$ and $Z$ alone (in particular, "independent of $X$ " if the marginal rate of substitution between them is independent of the quantity of $X$ ), and independence of the three goods $X, Y, Z$, to mean that (a) $Y Z$ is independent of $X$, (b) $X Z$ is independent of $Y$, and (c) $X Y$ is independent of $Z$, noting that in the integrable case (a) and (b) imply (c), since then "the marginal rate of substitution between any pair $X Y$ must then be of the form $f(x) / g(y)$, where $x$; $y$ are the quantities possessed." The proof supplied by Allen 
Allen's interpretation of Slutsky's paper deserves some comments on the question of non-integrability. This question is already discussed at length in his 1932 article, and he claims that a satisfactory theory of consumer choice must account for this most general case. According to Allen $(1932,223)$, the integrable case "means, in fact, that the individual can judge his relative preferences for widely separated combinations of goods, and this, in turn, means that the order in which the individual acquires the goods concerned is immaterial to him." Here he relies on Pareto's (1906b) aberrant attempt to take up the challenge posed by Volterra (1906) in his review of Pareto's Manuale (1906a), as well as on Pareto's subsequent treatments $(1909,1911)$ of the integrability problem, in which Pareto identified the mathemat-ical path of integration with the temporal order of consumption on the part of the consumer. ${ }^{29}$ The idea that (local) integrability has anything to do with the ability of the consumer to "judge his relative preferences between widely separated combinations of goods" seems to be original with Allen,

$(1934,214)$ used rather than proved this latter result (see also Allen and Bowley 1935, 138), since Hicks's definition implies (in the 3-good case) that " $X Y$ is independent of $Z$ " means that

$$
\frac{\partial u / \partial x}{\partial u / \partial y}=h(x, y) \text { for some function } \mathrm{h} \text {; }
$$

and this need not imply that $h(x ; y)$ has the form $f(x) / g(y)$. Hicks's claim may be proved by using Leontief's (1947) subsequent deep results. In terms of Leontief's notation, denoting $u_{x}^{\prime}=\partial u / \partial x$ and

$$
{ }_{x y} R=u_{y}^{\prime}{ }_{y} / u_{x}^{\prime} \text { and }{ }_{x y} R_{z}^{\prime}=\frac{\partial\left({ }_{x y} R\right)}{\partial z}=\frac{u_{y}^{\prime} u^{\prime \prime}{ }_{x z}-u_{x}^{\prime} u^{\prime \prime}{ }_{y z}}{\left[u_{y}^{\prime}\right]^{2}},
$$

Leontief's Theorem I implies that condition (a) is equivalent to

$$
{ }_{z y} R^{\prime}{ }_{x}=0 \Leftrightarrow u(x, y, z)=F(\phi(y, z), x) \text { for some } \phi, F,
$$

and likewise that condition (b) is equivalent to

$$
{ }_{z x} R_{y}^{\prime}=0 \Leftrightarrow u(x, y, z)=G(\psi(x, z), y) \text { for some } \psi, G .
$$

In Leontief's terminology, (a) implies that the set $\{Y, Z\}$ is locally functionally separable from the set $\{X, Y, Z\}$, and (b) implies that the set $\{X, Z\}$ is locally functionally separable from $\{X, Y, Z\}$. Since the sets $\{Y, Z\}$ and $\{X, Z\}$ overlap, Leontief's Theorem II implies that the utility function may be expressed in the additively separable form

$$
u(x, y, z)=\xi(x)+\eta(y)+\zeta(z)
$$

hence ${ }_{y x} R=\eta^{\prime}(y) / \xi^{\prime}(x)$, and thus ${ }_{y x} R_{z}^{\prime}=0$. As Schultz (1936) noted, this does in fact reduce to independence in the classical sense.

${ }^{29}$ On this, see Samuelson $(1950,361)$ as well as the annotations to the English translation of Pareto (1906b). 
but equally aberrant. ${ }^{30}$ His comment on this alleged economic assumption regarding the individual consumer does not leave any doubt:

This is obviously not true in general, and illustrates the severity of the assumption of integrability. (Allen 1932, 223n)

Thus, Allen's position seems to be not far from that of Cassel $(1918, \S 11,67 \mathrm{ff}$; $1932 \mathrm{a}, 72 \mathrm{ff} ; 1932 \mathrm{~b}, 80 \mathrm{ff}$ ) in denying the existence of a total ordering of commodity bundles by a consumer.

Writing at a time when he was himself skeptical of the utility concept, Samuelson (1938) had this to say concerning the principle of diminishing marginal rate of substitution: ${ }^{31}$

The introduction and meaning of the marginal rate of substitution as an entity independent of any psychological, introspective implications would be, to say the least, ambiguous, and would seem an artificial convention in the explanation of price behaviour. (This would be particularly so in the many-commodity, non-integrable case.) (Samuelson 1938, 62)

And regarding the terminology of "indifference directions" used by Allen, Samuelson twelve years later had this to say:

As behaviourists we have not yet earned the right to speak of "indifference" or "preference"; and we certainly have no right to speak of "indifference directions for infinitesimal or small movements", especially since the underlined words are by no means unambiguous or mutually equivalent. (Samuelson 1950, 365; italics in the original)

To invoke the principle of diminishing marginal rate of substitution along an indifference surface is one thing; but to invoke it along an uninterpretable "preference complex" when the differential equation $\sum_{i=1}^{n} \varphi_{i}(x) d x_{i}=0$ (where the $\varphi_{i}(x)$ are the Paretian "elementary ophelimities") is not integrable, is quite

\footnotetext{
${ }^{30}$ A hint of a distinction between local and global integrability was provided by Evans (1930, 120-2); see Debreu (1972) for a precise distinction.

31 Samuelson $(1938,61)$ followed Hicks and Allen (1934) in speaking of increasing marginal rate of substitution, but here we follow Hicks's revised terminology $(1939,20)$ diminishing marginal rate of substitution.
} 
another. $^{32}$

Against this uncompromising, even peremptory attitude, one can find a rationale for not taking into account the non-integrable case in Schultz's 1938 discussion of the issue:

What, then, can be done about the difficulty presented by the order of consumption which appears to undermine the very basis of our theory? It seems to me that an answer to this question is essentially at hand in the fact

32 Georgescu-Roegen $(1936,561 ; 1966,145)$ analyzed some examples in the case $n=2$ when there was a saturation point, and concluded that in the integrable case, the integral curves would consist of a family of concentric ellipsoids around the saturation point, while in the nonintegrable case they would consist of logarithmic spirals with the saturation point as a focus - even though the case $n=2$ is supposed to be the one in which "no integrabilitiy problem exists."

Samuelson $(1950,366)$ considered the intersection of a two-dimensional plane (say a budget plane) with a three-dimensional set of "planar elements" in the integrable and nonintegrable cases, and depicted the integral curves in this two-dimensional plane. In the integrable case these were either parallel indifference curves or elliptical curves surrounding the optimal point, whereas in the nonintegrable case they were logarithmic spirals.

Debreu $(1972,607)$ considered the case of logarithmic spirals surrounding a circle, showing that "global integrability is not a consequence of local integrability." This does not exhaust the possibilities, however.

If there is no satiation, we may consider as an example the total differential equation

$$
\sum_{i=1}^{3} \varphi_{i}\left(x_{i}\right) d x_{i} \equiv \frac{d x_{1}}{x_{1}}+\frac{d x_{2}}{x_{2}}+\frac{d x_{3}}{x_{1}+x_{2}+x_{3}}=0
$$

which does not satisfy the integrability condition

$$
\varphi_{1}\left(\frac{\partial \varphi_{2}}{\partial x_{3}}-\frac{\partial \varphi_{3}}{\partial x_{2}}\right)+\varphi_{2}\left(\frac{\partial \varphi_{3}}{\partial x_{1}}-\frac{\partial \varphi_{1}}{\partial x_{3}}\right)+\varphi_{3}\left(\frac{\partial \varphi_{1}}{\partial x_{2}}-\frac{\partial \varphi_{2}}{\partial x_{1}}\right)=0
$$

(cf. Wilson 1911, 255; Evans 1930, 119-20; Allen 1932, 222-3n; Hicks and Allen 1934, 211n; Debreu 1972, 606; Chipman and Moore 1976, 105). Suppose now that prices and income are all equal to unity, giving the budget plane $\sum_{i=1}^{3} x_{i}=1$. The intersection of the set of planar elements of (F1) with this plane gives a necessarily integrable differential equation of order 2 (cf. Wilson $1911,257-8)$, which in this case is

$$
\left(\frac{1}{x_{1}}-1\right) d x_{1}+\left(\frac{1}{x_{2}}-1\right) d x_{2}=0
$$

This integrates to

$$
\bar{u}\left(x_{1}, x_{2}\right)=\log x_{1}-x_{1}+\log x_{2}-x_{2},
$$

which is increasing for $0<x_{i}<1$ and concave. Within the unit simplex whose apex is $(0,0,1)$ and whose base is the segment joining $(1 ; 0 ; 0)$ to $(0 ; 1 ; 0)$, the function (F4) attains its minimum at the apex $(0 ; 0 ; 1)$ and its maximum at the midpoint of the base, $\left(\frac{1}{2}, \frac{1}{2}, 0\right)$. Thus, a number of puzzles in the integrability issue remain to be explored.

It should be noted that the above integrability conditions (F2), which are closely related to the Antonelli (1886) conditions, are the conditions which (together with the corresponding negative semi-definiteness conditions) are sufficient for the existence of a direct utility function, whereas the Slutsky symmetry and negative semi-definiteness conditions are sufficient for the existence of an indirect utility function (see the discussion in Chipman and Moore (1976, 103-9, 111-4), also Diewert (1977)). The indirect is easily obtainable from the direct utility function, by $v(p, s)=$ $u(x(p, s))$; Hurwicz and Uzawa $(1971,129-30$, Lemma 8) show, in effect, how to obtain a direct from an indirect utility function. 
that economic theory can approximate the facts of economic experience only if there is a routine in economic affairs (including the routine of change); when there is no routine, there can be no economic law. . . It appears, therefore, that too much attention has been attached in utility analysis to the problem of the order of consumption. Although it was introduced into economics by the eminent mathematician, Professor Vito Volterra, and although it was discussed at length by Pareto, it has little or no significance in an economy dominated by routine. (Schultz, 1938, 17)

Although Schultz (1938) in the above passage also followed Pareto (1906b) in interpreting nonintegrability as having to do with the "order of consumption", and erroneously attributed the idea to Volterra (1906), he was too good an applied econometrician not to know (as Allen should also have known from his work with Bowley (1935)) that family budgets do not provide data on the order of consumption but only on the total amount purchased per month or per year.

In his obituary to Slutsky, Allen (1950,212-3), while not losing the opportunity to deplore Slutsky's "mathematical scaffolding erected so painfully" and to remark that "his was the contribution of a mathematician", made it known that his preferred formulation of the theory of consumer choice was Samuelson's (1938, 1947) Weak Axiom of Revealed Preference. Ironically, Allen's paper appeared only two months after the publication of Houthakker's (1950) paper introducing the Strong Axiom, followed by Samuelson's (1950) article on the integrability problem. Allen's earlier stance is consistent with his acceptance of the weak but rejection of the strong axiom. This is in fact confirmed by his later discussion in which he refers to Samuelson (1948 and 1950):

Samuelson thought that a "strong axiom" could be laid down to guarantee integrability ... . It would seem, e.g. from Corlett and Newman (1952), that this is not the case. The revealed preference approach is no improvement on the simple assumption of an ordinal utility function and indifference map. (Allen 1956, 670)

Apparently, Corlett and Newman's objection to Houthakker's argument remained unchallenged until Hurwicz $(1971,177 \mathrm{n})$ pointed out that Corlett and Newman assumed that more than one integral surface could pass through any point of the 
commodity space (implying nondifferentiability of the "preference complex" at that point, so that the marginal rate of substitution there is not defined), which even Allen himself did not assume:

The basic axiom gives an indifference direction of change from any point (commodity combination), that specified by the marginal rate of substitution; it does not give a whole indifference locus unless the directions at various points can be "integrated" into such a locus. For this the marginal rates of substitution must satisfy a certain "integrability condition"; there is no apparent economic reason why they should, or indeed why they should not. (Allen 1956, 670)

Thus, Allen's stance in 1956 remained where it had been in 1932, while Samuelson, who like Allen had started out a skeptic regarding integrability (Samuelson 1938), had shed his skepticism in light of the logic of the revealed preference theory. ${ }^{33}$

It was shown by Kihlstrom, Mas-Colell, and Sonnenschein (1976) that a slightly weakened version of Samuelson's axiom (which they called the "weak weak axiom") is equivalent to negative semi-definiteness of the Slutsky matrix. ${ }^{34}$ On the other hand, the strong axiom implies the existence of a generating utility function, hence is equivalent to negative semi-definiteness plus symmetry of the Slutsky matrix. Symmetry alone is what Hurwicz $(1971,177)$ called

33 Allen also advances a perplexing argument $(1956,669-70)$ to the effect that if there is a transitive ordering of commodity bundles (whether total or not he does not say), the question of whether this ordering can be represented by a utility function is the "integrability problem"!

34 Samuelson's Weak Axiom of Revealed Preference states that if $p^{1} \cdot x^{1} \geqq p^{1} \cdot x^{2}$ and $x^{1} \neq x^{2}$, where the bundle $x^{1}$ was chosen at prices $p^{1}$ and income $p^{1} \cdot x^{1}$ (so that the bundle $x^{2}$ could have been chosen but wasn't), then it is not the case that $p^{2} \cdot x^{2} \geqq p^{2} \cdot x^{1}$, where $p^{2}$ is the price vector at which the bundle $x^{2}$ was chosen; i.e.,

$$
p^{1} \cdot x^{1} \geqq p^{1} \cdot x^{2} \text { and } x^{1} \neq x^{2} \Rightarrow p^{2} \cdot x^{1}>p^{2} \cdot x^{2}
$$

The "weak weak axiom" replaces this by

$$
p^{1} \cdot x^{1}>p^{1} \cdot x^{2} \Rightarrow p^{2} \cdot x^{1}>p^{2} \cdot x^{2}
$$

Samuelson $(1938 ; 1947,113)$ showed that the weak axiom implies that

$v^{\prime} K(p, s) v<0$ for all vectors $v$ not proportional to $p$,

where $K(p, s)$ is the not-necessarily-symmetric matrix of Slutsky terms $k_{i j}(p, s)$ (see also Georgescu-Roegen 1936). Gale (1960) showed, in effect, that the converse is not true. However, Kihlstrom and al. (1976) showed that the "weak weak axiom" is equivalent to the above negative semi-definiteness condition (which they described as "negative definiteness"). A simple proof and some extensions to these results have been provided by Jerison and Jerison (1993). 
"mathematical integrability", since it implies the existence of a family of integral surfaces which, however, need not be interpretable as indifference surfaces; "economic integrability", on the other hand, implies that, in addition, these are convex-to-the-origin indifference surfaces. ${ }^{35}$ Satisfaction of the weak but not the strong axiom (the postulates implicitly advocated by Allen), or in other words negative semi-definiteness but not symmetry of the Slutsky matrix, thus implies, as shown by Samuelson (1950) and first perceived by Georgescu-Roegen (1936), that the integral surfaces will be spirals permitting in principle the observation of transitive cycles of commodity bundles.

If the economic postulate of the "weak weak axiom" is equivalent to negative semi-definiteness of the Slutsky matrix, it is natural to inquire whether there is an economic postulate which exactly corresponds to its symmetry, and is therefore weaker than the strong axiom and does not imply the weak axiom. This would be the economic postulate corresponding to the "integrability case" decried by Allen. This question has been answered by Hurwicz and Richter (1979a, 1979b), who show that the desired postulate is an axiom of Ville (1946), which states that there must not be a cycle of commodity bundles each revealed strictly preferred to the previous one and the last revealed strictly superior to the original one. ${ }^{36}$

Slutsky was not far from stating the "economic" integrability conditions. It is true that Slutsky concentrated on symmetry as an empirical implication of his theory, but he also (in particular, in his criticism of Ricci) insisted on "stability"; and of course he used the fact that the diagonal elements of the Slutsky matrix are

\footnotetext{
${ }^{35}$ This terminology assumes that the budget constraint is that of a competitive economy, in which prices appear as parameters to the consumer. It is certainly quite conceivable, however, that a consumer could be shown (on the basis of questionnaires with binary comparisons) to have nonconvex-to-the-origin indifference curves, although of course the non-convex portions could not be observed in competitive equilibrium, but might be observed if the consumer had monopsonistic power. Thus, the terminology "economic integrability" might be misleading.

${ }^{36}$ While this seems very much like Houthakker's strong axiom of revealed preference, there is an important difference. Houthakker's axiom states that if there is a sequence of price vectors and commodity bundles $\left(p^{t}, x^{t}\right)_{t=1,2, \ldots, n}$ such that $p^{t} \cdot x^{t} \geqq p^{t} \cdot x^{t+1}$, where $x^{t}$ is the bundle bought at prices $p^{t}$, and if $x^{t} \neq x^{t+1}$, then it must follow that $p^{n+1} \cdot x^{n+1}<p^{n+1} \cdot x^{1}$; i.e., if each $x^{t}$ is revealed preferred to $x^{t+1}$ for $t=1,2, \ldots, n$, then $x^{n+1}$ must not be revealed preferred to $x^{1}$. A Ville cycle, on the other hand, has the above weak inequalities replaced by strict inequalities. A Ville cycle is a sequence $\left(p^{t}, x^{t}\right)$ such that $p^{t} \cdot x^{t}>p^{t} \cdot x^{t+1}$ for $t=1,2, \ldots, n$ and
} 
negative (Slutsky 1915, formulas [48] and [52]) in stating the "law of demand". However, he fell short of stating that the principal minors of the Slutsky matrix must oscillate in sign; this was added by Allen $(1938,510-11)$, Hicks $(1939,306)$, and Samuelson (1947), and in a related context by Hotelling (1935).

We may finally comment on Allen's argument that one of the principal contributions of Hicks and Allen (1934) was the replacement of the AuspitzLieben-Edgeworth-Pareto (ALEP) definition of (weak) complementarity between two commodities (namely $\partial^{2} u / \partial x_{i} \partial x_{j} \geq 0$ for $i \neq j$ ) by their concept of elasticity of complementarity, namely by the criterion that the elasticities of complementarity (or the compensated cross-elasticities of demand) be nonpositive ( $k_{i j} \leq 0$ in Slutsky's formulation). The latter is what Samuelson (1974) has called the Slutsky-Hicks-Allen-Schultz (SHAS) definition of complementarity. It was shown by Chipman (1977) that if the utility function $u$ is increasing and strongly concave, and if all distinct commodities are (weak) ALEP complements of each other, then the law of demand must hold: income elasticities of demand must be positive and demand for a commodity must be a decreasing function of its own price. ${ }^{37}$ Does this empirical implication hold for the SHAS definition? The answer is no, for the following simple reason. In the case $n=2$ it is necessarily the case when demand functions are differentiable (hence the Slutsky matrix is nonvanishing ${ }^{38}$ ) that the cross-Slutsky terms must be positive, hence the two commodities must be SHAS substitutes (even if they are ALEP complements!); ${ }^{39}$ but it is well known that Giffen's paradox can occur in this case. ${ }^{40}$ Similar

$p^{n+1} \cdot x^{n+1}<p^{n+1} \cdot x^{1}$. For further relevant results on Ville cycles see Shafer (1977) and Jerison and Jerison (1993).

${ }^{37}$ That ALEP complementarity affected the shapes of indifference curves had earlier been noted by Allen himself (1934a, 116-7; 1934b, 170ff), and later by Georgescu-Roegen (1952).

${ }^{38}$ Cf. Afriat (1972).

${ }^{39}$ In fact, it has recently been shown by Weber (1999b) that if $u$ is increasing and strongly concave, then if all distinct commodities are ALEP complements of each other then they must also be SHAS substitutes of each other. There is no reason to expect the converse to be true, however.

40 An example is given by Wold $(1948 ; 1953,102)$ of a utility function $u\left(x_{1}, x_{2}\right)=\log \left(x_{1}-1\right)-2 \log \left(2-x_{2}\right)$ defined in the region $x_{1}>1$ and $0<x_{2}<2$. The demand functions generated by this utility function are

$$
x_{1}=2+2 \frac{p_{2}}{p_{1}}-\frac{s}{p_{1}} \text { and } x_{2}=2 \frac{s}{p_{2}}-2 \frac{p_{1}}{p_{2}}-2 \text { for } p_{1}+p_{2}<s<p_{1}+2 p_{2} .
$$


problems with the SHAS definition led Samuelson (1974) to, in effect, rehabilitate the ALEP definition, but with the utility function an increasing, risk-tolcrant (i.e., concave and thus risk-averse) function of a well-defined "money-metric" utility function.

Despite a nostalgic attachment to the nonintegrable case in the nineteen fifties, Allen's original attachment to the nonintegrable case is traceable to a wish to dispense with the concept of utility, and more particularly with any psychological assumptions. The fact that he interpreted $\partial^{2} u / \partial x_{1} \partial x_{2}$ as an expression embodying psychological and palpable content, and $\partial^{2} u / \partial x_{1} \partial x_{2}=\partial^{2} u / \partial x_{2} \partial x_{1}$ as a psychological hypothesis regarding the order of consumption, is not to be regarded as an isolated fancy: he was acknowledging a Paretian line of interpretation of the integrability problem which was shared by Schultz and not rejected by Slutsky. Nevertheless it is not to be doubted that Allen went too far in considering the utility index function as a hedonistic concept. He thought that the assumption of diminishing marginal rate of substitution was deprived of all psychological assumptions contained in any index-utility approach towards consumer behavior.

\section{Hicks's Schultzian attitude}

Hicks's attitude toward Slutsky's contribution is much more qualified than Allen's, and exhibits the influence of Schultz regarding the interpretation of Slutsky's equation. The first thing that needs to be said is that Hicks does not share Allen's

We see that $\partial x_{1} / \partial=-1 / p_{1}$, so commodity 1 is an inferior good, and that if $2 p_{2}<s<p_{1}+2 p_{2}$ then $\partial x_{1} / \partial p_{1}=\left(s-2 p_{2}\right) / p_{1}^{2}>0$, so in this region it is also a Giffen good. The Slutsky matrix is verified to be

$$
2\left(p_{1}++2 p_{2}-s\right)\left[\begin{array}{cc}
-\frac{1}{p_{1}^{2}} & \frac{1}{p_{1} p_{2}} \\
\frac{1}{p_{1} p_{2}} & -\frac{1}{p_{2}^{2}}
\end{array}\right]
$$

which is symmetric and negative semi-definite.

It should be noted, however, that while $\partial u / \partial x_{1}=1 /\left(x_{1}-1\right)>0, \partial u / \partial x_{2}=2 /\left(2-x_{2}\right)>0$, and $\partial^{2} u / \partial x_{1} \partial x_{2}=0$, we have $\partial^{2} u / \partial x_{1}^{2}=-1 /\left(x_{1}-1\right)^{2}<0$ but $\partial^{2} u / \partial x_{2}^{2}=2 /\left(2-x_{2}\right)^{2}>0$, so $u$ is not concave; and in accordance with Slutsky's analysis $(1915,19 ; 1952,47)$, while commodity 2 (the "nonsatiating good") has increasing marginal utility, it is a superior good, but while commodity 1 (the "satiating good") has decreasing marginal utility, it is an inferior good. While $u$ is not concave, it is nevertheless strictly quasi-concave. 
attitude towards integrability. According to Hicks, pursuit of the nonintegrable case can be characterized as "chasing a will-o'-the wisp". 41

When more than two goods are being consumed, it is possible that the differential equation of the preference system may not be integrable. This point fascinates mathematicians, but it does not seem to have any economic importance at all, the only problems to which it could conceivably be relevant being much better treated by other methods. (Hicks 1939, 19n)

More than that, Hicks's attitude towards Slutsky's paper must be linked with the growing influence of the econometric field in the thirties. In our view, this is most striking with regard to both the interpretation of Slutsky's equation and the definition of substitutes and complements in consumption. Hicks's 1937 mathematical essay is a first step toward a break with the 1934 presentation of the Slutsky equation, given that he is adopting both the differential and the elasticity presentation of the Slutsky equation, and in Value and Capital he finally gives up the elasticity presentation. ${ }^{42}$ Regarding the interpretation of Slutsky's equation, Hicks (1939) is showing allegiance both to Hicks and Allen's 1934 presentation and to the original Slutsky interpretation. Indeed, as Mosak (1942) first noticed, Hicks does not provide the same interpretation in the text as in the appendix. According to Hicks $(1939,31-32)$, the substitution effect represents the change in the demand for good 1 , if the price change $d p$, is accompanied by a compensated variation in money income so as to keep the individual on the same indifference curve (the same level of "real income") as before the price change. ${ }^{43}$ This

\footnotetext{
${ }^{41}$ Samuelson $(1950,357)$ does not hesitate to underline this difference: "He [Allen] entertains the hypothesis of non-integrability; and if I dare impute any differences to the separate components of the Hicks-Allen composite commodity, I would say that Hicks consistently rules out the nonintegrability case, while Allen accepts it as the more general hypothesis." In Hicks and Allen $(1934,72)$, Hicks stated that we can consider "as a general rule" that the integrability conditions are satisfied.

${ }^{42}$ But he later remarks (Hicks 1981, 5): "What I do regret is the disappearance, from most of my later work, of the Fundamental Formula in elasticity form. The Slutsky form, which I took over for [Value and Capital ], is mathematically convenient, but loses some economic virtue."

${ }^{43}$ According to Mosak (1942, 70-71), Hicks's mathematical investigation of the substitution effect would be better interpreted by considering the substitution effect first, and thus by measuring this effect on the original indifference curve, and not on the new one (which is a higher curve in case of a price decrease). Mosak (1942), who succeeded Milton Friedman as research assistant to Schultz in 1935 (Schultz 1938, xi), also refers to Schultz's translation of Slutsky's article.
} 
interpretation, in fact, differs from Slutsky's own interpretation. Mosak (1942) will sum up this paradoxical difference:

The difference between the Hicks and Slutsky interpretations is readily apparent. Whereas Hicks interprets $\left[k_{i j}\right]$ as measuring the substitution effect that would result if money income were adjusted so as to leave real income actually unchanged, Slutsky interprets it as measuring the substitution effect that would result if money income were adjusted so as to leave real income apparently unchanged. Whereas Hicks's substitution effect involves a change in demand along a given indifference curve, Slutsky's "substitution effect" involves a change from a lower to a higher indifference curve. Yet surprisingly enough, both of these effects are measured by one and the same term, $\left[k_{i j}\right]$. (Mosak 1942, 73)

Mosak also notices that Hicks's interpretation in the Appendix is identical with Slutsky's original presentation. ${ }^{44}$ On the one hand, Hicks keeps the antecedent illustration he had given in 1934 (Hicks and Allen 1934, 66); on the other hand, he interprets it consistently with the Slutsky presentation in the Appendix. The fact is that, in the Appendix excepted, Hicks does not provide a precise definition of what he means by a change in "real income". In his 1935 paper, Schultz had devoted careful attention to the meaning of "real income", 45 and had provided a careful illustration of Slutsky's equation. Why Hicks chose to provide two distinct interpretations of the Slutsky equation is not quite evident, but the presentation in

\footnotetext{
${ }^{44}$ He was further followed by Samuelson $(1947,184)$, who does not refer to Mosak. But it is quite possible that this passage in the Foundations had already been written in 1942. In fact, Mosak $(1942,73 n)$ shows that Slutsky's and Hicks's interpretations are identical in the limit. See also MasColell et al. $(1995,72)$ who, although not referring to Mosak, discuss the "remarkable conclusion that the derivative of the Hicksian demand function is equal to the derivative of this alternative Slutsky compensated demand" (italics in original). On all this see the illuminating analysis by Samuelson $(1953,7-8)$.

45 "By the 'real income of an individual' I mean the utility which he derives from the combination of economic goods and services which he consumes during a given interval of time. Two combinations represent the same real income and are said to be equivalent if they lie on the same indifference curve. The money income which leaves the real income of an individual actually unchanged in a new price situation is such as will induce him to buy a combination of goods which he considers equivalent to the original. The money income which leaves the real income of an individual apparently unchanged in a new price situation may be defined as one which enables him to buy the identical combination of goods as the original. The apparent money income minus the original money income may be called the apparent loss or gain, according as it is positive or negative." (Schultz 1935, 444n).
} 
the Appendix may well come directly from Schultz. ${ }^{46}$ We may suggest that while the first interpretation is more suitable as a rhetorical justification of the law of demand - the emphasis being put on the negative substitution effect along an indifference curve -, the Schultzian interpretation is more adapted to empirical testing. Here we come to the second point of the argument, regarding the definition of complementarity. It is to be remembered that according to Schultz, Hicks and Allen (1934) did not provide a definition of complementarity for the case of more than three goods. Actually, Hicks and Allen $(1934,67)$ suggested a way out of this. Instead of considering the elasticity of substitution between $\mathrm{X}$ and $\mathrm{Y}$, they proposed to consider the elasticity of substitution between $\mathrm{X}$ and "all the other goods taken together". Thus, the idea is to consider a composite commodity made up of all the other goods, and that "these latter goods remain freely substitutible for each other at fixed ratios given by their relative prices". Such a procedure is also available in the theory of complementarity, except that the composite good is made up of all goods other than the pair considered. Hicks will deal more systematically with this in Value and Capital. In order to keep close to the 1934 definition, he makes the assumption that the relative prices of the goods comprising the composite commodity are fixed (Hicks, 1939, 33). Imperceptibly, Hicks $(1939,44$ and 46) tends to identify this composite good with money (the numéraire). In the Appendix (Hicks 1939, 311), he does not mention the peculiar hypothesis under which the concept was constructed, and he adopts a definition of complementarity identical with that of Schultz (1935). ${ }^{47}$ To that extent, it is reasonable to think that during the period 1934-1938, Hicks was increasingly influenced by Schultz's methodological arguments. As evidence of this, the preface to the first edition of Value and Capital ends with the idea that "the place of economic theory is to be the servant of applied economics" (Hicks 1939, v). He

\footnotetext{
${ }^{46}$ It is to be noted also that Hicks (1956, ch. VII) provides a comparative statement and appraisal of both interpretations.

${ }^{47}$ As far as we are able to know, this point was first made by Samuelson $(1947,184-5 \mathrm{n})$ who clearly identifies that "the difficulty may reside in Hicks's unique use of the concept 'money' ". Samuelson $(1974,1286)$ later conceded that those definitions were not so different after all. The turning point lies in the exact definition of "money". This was already pointed out in Samuelson (1950, 379): "In 1939 Hicks seems to have abandoned this definition in favor of the SlutskySchultz definitions. For $n=3$, the results of either definition are qualitatively the same. For $n>3$,
} 
was even more precise in the preface to the French edition (1955), where he added that "the first part of the book, dealing with the theory of demand, was inspircd by the works of old econometricians, particularly by the articles of Henry Schultz" (Hicks 1955, vii). ${ }^{48}$

\section{Conclusion}

As far as we can tell, Slutsky's paper was rediscovered by Dominedò and thereafter, and independently of each other, by Schultz and by Hicks and Allen. His work was praised for providing the most general restrictions on demand behavior. But a careful scrutiny of the arguments also shows that Slutsky (1915) was not appreciated in the same way by the protagonists, and that his article soon became the object of a methodological dispute. More precisely, it is not to be doubted that Allen and Schultz did not share the same interpretation of Slutsky (1915). Whereas Schultz took Slutsky's (1915) treatment as more adapted to quantitative estimation, Allen regarded it as a particular case of a general theory based on diminishing marginal rate of substitution. As for Hicks, he finally adopted Schultz's definition of complementarity. To that extent, that Allen was not cited by Schultz $(1935,1938)$ as an independent discoverer of Slutsky (1915) together with Hicks may in fact suggest that he was not very interested in his work. This would also be another irony, given that Allen's paper (1936) is regarded as the first tribute to Slutsky.

\section{Appendix: Further possible sources of the rediscovery}

The discussion in section 1 was based on published sources of information concerning the rediscovery of Slutsky's article. Here we enter the realm of conjecture, which may perhaps be confirmed or rejected by later scholars who have access to more information

\footnotetext{
this is not true. If we define all but the two goods in question to be a Hicksian composite commodity, the Slutsky-Hicks definition can be cast in Hicks-Allen terminology."

${ }^{48}$ In curious contrast with this tribute is Hicks's later statement $(1979,202 ; 1984,287)$, commenting on his first visit to the United States in 1946: "I have felt little sympathy with theory for theory's sake, which has been characteristic of one strand in American economics; nor with the idealisation of the free market, which has been characteristic of another; and I have little faith in the econometrics, on which they have so largely relied to make their contact with reality."
} 
than we have been able to retrieve. One interesting conjecture is that a possible source of Hicks's discovery was Jacob Marschak. Marschak was born in Kiev on July 23, 1898, and attended lectures by Slutsky. According to a recorded interview Marschak had this to say:

Recently I read an obituary of Evgenii Evgen'evich Slutskii, who later [than 1910] was my teacher of statistics in the Institute of Economics, and still later became quite famous as a member of the Academy of Sciences. He was one of the founders of mathematical economics. One of his publications, in an Italian journal of 1913 [sic], is quite fundamental. (Marschak 1971, 11)

Marschak emigrated to Germany in 1919 (Marschak 1971, 76) to study economics at Heidelberg University where he obtained a doctorate in 1922, then went to the Institut für Weltwirtschaftlich in Kiel, and obtained his Habilitation from Heidelberg in 1933 (cf. Hagemann and Krohn 1992, 178); ${ }^{49}$ his thesis, on the elasticity of demand (Marschak 1931), made no mention of Slutsky, however. In 1933 - the very year in which Hicks was presumably working on his paper with Allen, but in London, not Oxford - Marschak went to Oxford University as a lecturer, where he stayed as Reader and Director of the Institute of Statistics until his move to the United States in 1939. (Hicks did not move to Oxford until $1946^{50}$ ). His son, Thomas Marschak, wrote to one of us as follows:

My father was indeed born in Kiev (1898) and spent most of his youth there. In 1919, when the Bolsheviks started to consolidate their power, he left for Germany.

My father stayed in Germany until 1933 and then moved to Oxford, ... I don't know whether those dates are consistent with your idea that my father might have been the transmission channel for Slutsky's ideas. ... I don't recall talking with my father about this, though he did mention Slutsky a number of times. (Thomas Marschak, letter to JSC, 12 March 1999)

We must leave for later scholars to determine whether Hicks met Marschak in 1933 and whether conversations took place between them regarding Slutsky (1915).

\footnotetext{
${ }^{49}$ We are grateful to Harald Hagemann for supplying us with a copy of Marschak (1971).

${ }^{50}$ Hicks taught at the London School of Economics during 1926-35; spent 1935-38 at Cambridge where he wrote Value and Capital ; then 1938-46 at the University of Manchester, 1946-52 at Nuffield College, and 1952-65 as Drummond Professor at Oxford. Cf. Hicks (1979 and 1984).
} 
A final, somewhat more tenuous, connection is suggested be Le Gall (1996) who, in the process of discussing the controversial finding by Henry Ludwell Moore $(1914,114-$ 5) that the own price elasticity of demand for pig-iron was positive, made the following comment regarding the rediscovery of Slutsky's paper:

...contrary to the opinion expressed by Hicks in Value and Capital (1939, 19) according to which Slutsky's work was totally unknown to western economists, Moore, in the course of a correspondence with Slutsky, became aware of the income and price effects [here was inserted a footnote: See in particuliar Moore (1917)], which according to him would affect the forms of demand functions over time. (Le Gall 1996, 307)

Le Gall presented no documentation to support this contention. There was no mention of Slutsky in Moore (1917), although the latter referred to an article in Italian on methods of interpolation by Pareto (1907) (see Moore 1917, 172n). It is possible that Moore was more interested in Slutsky's contributions to statistics than to economic theory. ${ }^{51}$ If it is true, however, that Moore was acquainted with Slutsky (1915), this is certainly of interest, given that Moore was Schultz's thesis advisor (cf. Stigler 1962, 17) and that Schultz's 1938 book was dedicated to him. We do not know whether any of Schultz's unpublished papers and correspondence are extant; but presumably he remained in contact with Moore in the early 1930s. However, we know from Stigler $(1962,3)$ that Moore retired from Columbia in 1929 owing to a "nervous collapse", and 1929 was the date of his last published work, so it seems rather doubtful that he was actively engaged in academic pursuits during the rest of his life.

\section{References}

Afriat, S. (1972) "The Case of the Vanishing Slutsky Matrix." Journal of Economic Theory, 5 (October), 208-223.

Allen, R. G. D. (1932) "The Foundations of a Mathematical Theory of Exchange." Economica, 12 (May), 197-226.

Allen, R. G. D. (1934a) "The Nature of Indifference Curves." Review of Economic Studies, 1 (February), 110-121.

Allen, R. G. D. (1934b) "A Comparison between Different Definitions of Complementary and Competitive Goods." Econometrica, 2 (April), 168-175.

51 On the other hand, Schultz $(1931 b, 658-660 ; 1938,50-51)$ drew attention to Moore's discussion $(1917,150)$ of Pareto's recognition of the possibility of upward sloping demand curves when preferences are not additively separable. 
Allen, R. G. D. (1936) "Professor Slutsky's Theory of Consumer's Choice." Review of Economic Studies, 3 (February), 120-129.

Allen, R. G. D. (1938) Mathematical Analysis for Economists. London: Macmillan and Co., Limited.

Allen, R. G. D. (1950) “The Work of Eugen Slutsky.” Econometrica, 18 (July), 209-216.

Allen, R. G. D. (1956) Mathematical Economics. London: Macmillan \& Co Ltd, 1956. Second edition, 1960.

Allen, R. G. D. and Bowley, A. L. (1935) Family Expenditure. London: P. S. King \& Son, Ltd.

Antonelli, G. B. (1886) Sulla teoria matematica della economia politica. Pisa: Tipografia del Folchetto. English translation, "On the Mathematical Theory of Political Economy," in Chipman, Hurwicz, Richter, and Sonnenschein (1971), 332-364.

Auspitz, R. and Lieben, R. (1889) Untersuchungen über die Theorie des Preises. Leipzig: Verlag von Duncker \& Humblot. French translation, Recherches sur la théorie du prix, 2 vols. (Texte and Album). Paris: M. Giard \& E. Brière, 1914.

Backhouse, R. E., Hausman, D. M., Mäki, U., and Salanti A. (eds.) (1998) Economics and Methodology: Crossing Boundaries. Proceedings of the IEA Conference held in Bergamo (Italy). London and Basingstoke: The Macmillan Press.

Bridgman, P. W. (1927) The Logic of Modern Physics. New York: The Macmillan Company.

Cassel, G. (1918-32) Theoretische Sozial Ökonomie. Leipzig: C. F. Wintersche Verlagshandlung,

1918. 5th edition, Leipzig: A. Deichertsche Verlagsbuchhandlung Dr. Werner Scholl, 1932a. English translation, The Theory of Social Economy, 2 vols. London: Ernest Benn Limited, 1932b.

Chipman, J. S. (1971) "Introduction to Part II." In Chipman, Hurwicz, Richter, and Sonnenschein (1971), 321-31.

Chipman, J. S. (1974) "Homothetic Preferences and Aggregation." Journal of Economic Theory, 8 (May), 26-38.

Chipman, J. S. (1976) "The Paretian Heritage." Revue européenne des Sciences Sociales et Cahiers Vilfredo Pareto, 14 (No. 37), 65-173.

Chipman, J. S. (1977) "An Empirical Implication of Auspitz-Lieben-Edgeworth-Pareto Complementarity," Journal of Economic Theory, 14 (February), 229-231.

Chipman, J. S., Hurwicz, L., Richter, M. K., and Sonnenschein, H. F. (eds.) (1971) Preferences, Utility, and Demand. New York: Harcourt Brace Jovanovich, Inc.

Chipman, J. S. and Moore, J. C. (1976) "The Scope of Consumer's Surplus Arguments." in A. M. Tang, F. M. Westfield, and J. S. Worley (eds.), Evolution, Welfare, and Time in Economics. Lexington, Mass.: D. C. Heath and Company, 69-123.

Corlett, W. J. and Newman, P. K. (1952) "A Note on Revealed Preference and the Transitivity Condition." Review of Economic Studies, 20 (No. 2), 156-158.

Court, L. M. (1941) "Invariable Classical Stability of Entrepreneurial Demand and Supply Functions." Quarterly Journal of Economics, 56 (November), 134-144.

Debreu, G. (1972) "Smooth Preferences." Econometrica, 40 (July), 603-615. "Smooth Preferences: A Corrigendum.” Econometrica, 44 (July 1976), 831-832. 
Debreu, G. (1974) "Excess Demand Functions." Journal of Mathematical Economics, 1 (March), 15-21.

Diewert, W. E. (1977) "Generalized Slutsky Conditions for Aggregate Consumer Demand Functions." Journal of Economic Theory, 15 (August), 353-362.

Dominedò, V. (1933) "Considerazioni interno alla teoria della domanda." Giornale degli Economisti e Rivista di Statistica [3], 73 (January, November), 30-48, 765-807.

Edgeworth, F. Y. (1897) "La teoria pura del monopolio." Giornale degli Economisti [2], 15 (July, October, November), 13-31, 307-320, 405-414. English Translation, "The Pure Theory of Monopoly", in Edgeworth (1925), vol. 1, 111-42.

Edgeworth, F. Y. (1915) "Recent Contributions to Mathematical Economics." Economic Journal, 25 (March, June), 36-63, 189-203. Reprinted as "On Some Theories due to Pareto, Zawadski, W. E. Johnson and Others," in Edgeworth (1925), vol. 2, 450-491.

Edgeworth, F. Y. (1925) Papers Relating to Political Economy, 3 vols. London: Macmillan.

Evans, G. C. (1930) Mathematical Introduction to Economics. New York: McGraw-Hill Book Company, Inc.

Fanno, M. (1926) Contributo alla Teoria Economica dei Beni Succedanei. Milano: Università Cobboni Editrice. In Annali di Economia, 2, 329-471.

Fanno, M. (1929) "Die Elastität der Nachfrage nach Ersatzgutern." Zeitschrift für National Ökonomie, 1 (May), 51-74.

Fanno, M. (1931) "Cicli di produzione, cicli del credito e fluttuazioni industriali." Giornale degli Economisti e Rivista de Statistica [4], 46 (May), 329-370.

Fisher, I. (1892) "Mathematical Investigations in the Theory of Value and Prices." Transactions of the Connecticut Academy, 9 (July), 1-124. Reprinted, New Haven: Yale University Press, 1925, and New York: Augustus M. Kelley, Inc., 1961.

Friedman, Milton (1934) "The Fitting of Indifference Curves as a Method of Deriving Statistical Demand Curves." Manuscript.

Georgescu-Roegen, N. (1936) "The Pure Theory of Consumer's Behavior." Quarterly Journal of Economics, 50 (August), 545-93.

Georgescu-Roegen, N. (1952) "A Diagrammatic Analysis of Complementarity." Southern Economic Journal, 19 (July), 1-20.

Gorman, W. M. (1953) “Community Preference Fields." Econometrica, 21 (January), 6380.

Green, E. J. and Moss, K. A. (1993) "The Reorientation of Neoclassical Consumer Theory." In T. Horowitz and A. I. Janis (eds.), Scientific Failure (Lanham, MD: Rowman \& Littlefield Publishers), 49-78.

Hagemann, H. and Krohn, C-D. (1992) Die Emigration deutschsprachiger Wirtschaftswissenschaftler nach 1933: Biographische Gesamtübersicht. 2. Auflage. Stuttgart: Diskussionsbeitrage aus dem Institut fur Volkswirtschaftslehre (520), Universität Hohenheim.

Hands, D. W. (1993) "More Light on Integrability, Symmetry, and Utility as Potential Energy in Mirowski's Critical History." In Neil de Marchi (ed.), Non-Natural Social Science: Reflecting on the Enterprise of More Heat than Light, Annual Supplement to volume 25, History of Political Economy, Durham and London: Duke University Press, 118-30. 
Hands, D. W. and Mirowski, P. (1998) "Harold Hotelling and the Neoclassical Dream." In Backhouse et al. (1998), 322-97.

Hicks, J. R. (1933) "Gleichgewicht und Konjunktur." Zeitschrift für National Ökonomie, 4 (Heft 4), 441-455.

Hicks, J. R. (1937) Théorie mathématique de la valeur en régime de libre concurrence. Paris, Hermann \& $\mathrm{C}^{\text {ie }}$, ćditcurs.

Hicks, J. R. (1939) Value and Capital. Oxford: at the Clarendon Press. 2nd edition, 1946.

Hicks, J. R. (1955) Préface à l'édition française de Valeur et Capital. Paris: Dunod, 1956, vii-viii.

Hicks, J. R. (1956) A Revision of Demand Theory. Oxford: at the Clarendon Press.

Hicks, J. R. (1970) "Elasticity of Substitution Again: Substitutes and Complements." Oxford Economic Papers, 22 (November), 289-296. Revised version, "Elasticity of Substitution Reconsidered," in Hicks (1983), 312-326.

Hicks, J. R. (1979) "The Formation of an Economist." Banca Nazionale del Lavoro Quarterly Review, (September), 195-204. Reprinted in Hicks (1984), 281-290.

Hicks, J. R. (1980) "Equilibrium and the Trade Cycle" (English translation of Hicks 1933), Economic Inquiry, 18 (October), 523-534. Reprinted in Hicks (1982), 28-41.

Hicks, J. R. (1981) Collected Essays on Economic Theory, Vol. I: Wealth and Welfare. Oxford: Basil Blackwell, and Cambridge, Mass.: Harvard University Press.

Hicks, J. R. (1982) Collected Essays on Economic Theory, Vol. II: Money, Interest and Wages. Oxford: Basil Blackwell.

Hicks, J. R. (1983) Collected Essays on Economic Theory, Vol. III: Classics and Moderns. Oxford: Basil Blackwell, and Cambridge, Mass: Harvard University Press.

Hicks, J. R. (1984) The Economics of John Hicks. Oxford: Basil Blackwell.

Hicks J. R. and Allen, R. G. D. (1934) "A Reconsideration of the Theory of Value," Parts I and II. Economica, N.S., 1 (February, May), 52-76, 196-219. Reprinted in Hicks (1981), 114-132.

Hotelling, H. (1932) "Edgeworth's Taxation Paradox and the Nature of Demand and Supply Functions." Journal of Political Economy, 40 (October), 577-616.

Hotelling, H. (1935) "Demand Functions with Limited Budgets," Econometrica, 3 (January), 66-78.

Houthakker, H. S. (1950) "Revealed Preference and the Utility Function." Economica, N. S., 26 (May), 159-174.

Hurwicz, L. (1971) "On the Problem of Integrability of Demand Functions." In Chipman, Hurwicz, Richter, and Sonnenschein (1971), 174-214.

Hurwicz, L. (1998) "Harold Hotelling and the Neoclassical Dream: Comment." In Backhouse et al. (1998), 398-416.

Hurwicz, L. and Richter, M. K. (1979a) "An Integrability Condition with Applications to Utility Theory and Thermodynamics." Journal of Mathematical Economics, 6 (March), 7-14.

Hurwicz, L. and Richter, M. K. (1979b) "Ville Axioms and Consumer Theory." Econometrica, 47 (May), 603-619. 
Hurwicz, L. and Uzawa, H. (1971) "On the Integrability of Demand Functions." In Chipman, Hurwicz, Richter, and Sonnenschein (1971), 114-148.

Jerison, D. and Jerison, M. (1993) "Approximately Rational Consumer Demand." Economic Theory, 3 (No. 2), 217-241.

Johnson W. E. (1913) "The Pure Theory of Utility Curves." Economic Journal, 23 (December), 483-513.

Jorgenson, D. W. (1997) Welfare. Volume 1: Aggregate Consumer Behavior. Cambridge, Mass.: The MIT Press.

Jorgenson, D. W. and Lau, L. J. (1977) "Statistical Tests of the Theory of Consumer Behavior." In H. Albach, E. Helmstädter, and R. Henn (eds.), Quantitative Wirtschaftsforschung: Wilhelm Krelle zum 60. Geburtstag. Tübingen: J. C. B. Mohr, 383-394. Reprinted in Jorgenson (1997), 29-90.

Jorgenson, D. W. and Lau, L. J. (1979) "The Integrability of Consumer Demand Functions." European Economic Review, 12 (April), 115-147. Reprinted in Jorgenson (1997), 103-136.

Jorgenson, D. W. and Lau, L. J. (1986) "Testing the Integrability of Consumer Demand Functions, United States, 1947-1971." In D. Slottje (ed.), Advances in Econometrics, Vol. 5. Greenwich, Connecticut: JAI Press, 31-48. Reprinted in Jorgenson (1997), 137152.

Kihlstrom, R., Mas-Colell, A., and Sonnenschein, H. (1976) "The Demand Theory of the Weak Axiom of Revealed Preference." Econometrica, 44 (September), 971-8.

Lange, O., McIntyre, F., and Yntema, T. O. (eds.) (1942) Studies in Mathematical Economics and Econometrics: In Memory of Henry Schultz. Chicago: University of Chicago Press.

Le Gall, P. (1996) "Une énigme de l'histoire de l'économétrie: l'éetrange demande de lingots de fonte de Henry Moore (1914)." Revue d'économie politique, 106 (MarchApril), 293-318.

Legris, A. (1995) "La théorie économique italienne de l'entre-deux-guerres." Revue économique, 46 (January), 91-113.

Leontief, W. (1947) "A Note on the Interrelation of Subsets of Independent Variables of a Continuous Function with Continuous First Derivatives." Bulletin of the American Mathematical Society, 53 (April), 343-350.

Mantel, R. (1974) "On the Characterization of Aggregate Excess Demand Functions." Journal of Economic Theory, 7 (March), 348-353.

Mas-Colell, A., Whinston, M. D., and Green, J. R. (1995). Microeconomic Theory. New York and Oxford: Oxford University Press.

McFadden, D. L., Mantel, R., Mas-Colell, A., and Richter, M. K. (1974) “A Characterization of Community Excess Demand Functions." Journal of Economic Theory, 9 (December), 361-374.

McKenzie, L. W. (1957) "Demand Theory Without a Utility Index." Review of Economic Studies, 24 (June), 185-189.

Marschak, J. (1931) Elastizität der Nachfrage. Tübingen: Verlag von J. C. B. Mohr (Paul Siebeck). 
Marschak, J. (1971) Recollections of Kiev and the Northern Caucasus, 1917-18. An Interview Conducted by Richard A. Pierce. University of California, Berkeley; Bancroft Library, Regional Oral History Office.

Mirowski, P. (1998) "Operationalism." In Davis, J. B., Hands, D. W., and Mäki, U. (eds.), The Handbook of Economic Methodology. Aldershot, Hants: Edward Elgar Publishing, 346-349.

Moore, H. L. (1914) Economic Cycles: Their Law and Cause. New York: The Macmillan Company.

Moore, H. L. (1917) Forecasting the Yield and the Price of Cotton. New York: The Macmillan Company.

Mosak, J. (1942) "On the Interpretation of the Fundamental Equation of Value Theory." In Lange et al. (1942), 69-74.

Nataf, A. (1953) "Sur des questions d'agrégation en économétrie." Publications de l'Institut de Statistique de l'Université de Paris, 2 (Fasc. 4), 5-61.

Newman, P. K. and Read, R. C. (1958) "Demand Theory Without a Utility Index Comment." Review of Economic Studies, 25 (June), 197-199.

Pareto, V. (1892-93) "Considerazioni sui principii fondamentali dell'economia politica pura." Giornale degli Economisti, [2], 4 (May 1892), 389-420; 4 (June 1892), 485-512; 5 (August 1892), 119-157; 6 (January 1893), 1-37; 7 (October 1893), 279-321. In Pareto, Ecrits d'économie politique pure, volume 26 of Euvres Complètes, Geneva: Droz, 1982.

Pareto, V. (1906a) Manuale di economia politica. Milan: Società Editrice Libraria.

Pareto, V. (1906b) "L'ofelimità nei cicli non chiusi." Giornale degli Economisti [2], 33 (July), 15-30. English translation: "Ophelimity in Nonclosed Cycles," in Chipman, Hurwicz, Richter, \& Sonnenschein (1971), 370-385.

Pareto, V. (1907-08) "L'interpolazione per la ricerca delle leggi economiche," Giornale degli Economisti [2], 34 (May 1907), 366-385; 35 (June 1908), 423-453.

Pareto, V. (1909) Manuel d'économie politique. Paris: V. Giard et E. Brière. Reprinted, Paris: Marcel Giard, 1927, and Geneva: Droz, 1981.

Pareto, V. (1911) “Économie mathématique." Encyclopédie des Sciences mathématiques, Tome I, Vol. IV, Fasc. 4. Paris: Gauthiers-Villars, 591-640.

Ricci, U. (1904) "Curve crescenti di ofelimit $\mu$ a elementare e di domanda." Giornale degli Economisti [2], 29 (August), 112-138.

Ricci, U. (1915) "Confronti fra medie." Giornale degli Economisti e Rivista di Statistica [3], 51 (July), 38-66.

Ricci, U. (1924) "Elasticità dei bisogni, della domanda e dell'oferta." Giornale degli Economisti e Rivista de Statistica, [3], 64 (August, October), 413-431, 509-531.

Ricci, U. (1932a) "Può una curva di domanda esser crescente?" Giornale degli Economisti e Rivista di Statistica, [3], 72 (April), 197-240.

Ricci, U. (1932b) "The Psychological Foundations of the Law of Demand." Journal of Political Economy, 40 (April), 145-185.

Ricci, U. (1933) "On the Demand for Rival (or Substitute) Commodities." Econometrica, 1 (April), 181-189.

Ricci, U. (1935) "The Modification of the Utility Curve for Money in the Cases of Indivisible Goods and Goods of Increasing Utility." Economica, N.S., 2 (May), 168-197. 
Samuelson, P. A. (1938) "A Note on the Pure Theory of Consumer's Behaviour." Economica, N.S., 5 (February), 61-71. “An Addendum.” Ibid., 5 (August), 353-354.

Samuelson, P. A. (1942) "Constancy of the Marginal Utility of Income." In Lange et al. (1942), 75-91.

Samuelson, P. A. (1947) Foundations of Economic Analysis. Cambridge, Mass.: Harvard University Press.

Samuelson, P. A. (1948) "Consumption Theory in Terms of Revealed Preference." Economica, N.S., 15 (November), 243-253.

Samuelson, P. A. (1950) "The Problem of Integrability in Utility Theory." Economica, N.S., 17 (November), 355-85.

Samuelson, P. A. (1953) "Consumption Theorems in Terms of Over-Compensation Rather than Indifference Comparisons." Economica, N.S., 20 (February), 1-9.

Samuelson, P. A. (1974) "Complementarity: An Essay on the 40th Anniversary of the Hicks-Allen Revolution in Demand Theory." Journal of Economic Literature, 12 (December), 1255-89.

Samuelson, P. A. (1998) "How Foundations Came to Be." Journal of Economic Literature, 36 (September), 1375-1386.

Schultz, H. (1928) The Statistical Laws of Demand and Supply, with Special Application to Sugar. Chicago: The University of Chicago Press.

Schultz, H. (1931a) "The Italian School of Mathematical Economics." Journal of Political Economy, 39 (February), 76-85.

Schultz, H. (1931b) "Henry L. Moore's Contribution to the Statistical Law of Demand." In Stuart Rice (ed.), Methods in Social Science (Chicago: The University of Chicago Press), 645-661.

Schultz, H. (1933) "Interrelations of Demand." Journal of Political Economy, 41 (August), 468-512.

Schultz, H. (1935) "Interrelations of Demand, Price, and Income." Journal of Political Economy, 43 (August), 433-481.

Schultz, H. (1936) Review of Family Expenditure, by R. G. D. Allen and A. L. Bowley. Journal of the American Statistical Association, 31 (September), 613-617.

Schultz, H. (1938) The Theory and Measurement of Demand. Chicago: University of Chicago Press.

Shafer, W. J. (1977) "Revealed Preference Cycles and the Slutsky Matrix." Journal of Economic Theory, 16 (December), 293-309.

Slutsky, E. (1915) "Sulla teoria del bilancio del consumatore." Giornali degli Economisti e Rivista di Statistica [3], 51 (July), 1-26. English translation, "On the Theory of the Budget of the Consumer," in G. J. Stigler and K. E. Boulding (eds.), Readings in Price Theory. Homewood, Illinois: Richard D. Irwin, Ltd., 1952, 27-56.

Sonnenschein, H. (1972) "Market Excess Demand Functions." Econometrica, 40 (May), 549-563.

Sonnenschein, H. (1973) "Do Walras' Identity and Continuity Characterize the Class of Community Excess Demand Functions?" Journal of Economic Theory, 6 (August), 345354. 
Stigler, G. J. (1962) "Henry L. Moore and Statistical Economics." Econometrica, 30 (January), 1-21.

Theil, H. (1954) Linear Aggregation of Economic Relations. Amsterdam: North-Holland.

Ville, J. (1946) "Sur les conditions d'existence d'une ophélimité totale et d'un indice du niveau des prix." Annales de l'Universitée de Lyon [3A], 32-39. English translation, "The Existence Conditions of a Total Utility Function." Review of Economic Studies, 19 (No. 2, 1952), 123-128.

Volterra, V. (1906) "L'economia matematica ed il nuovo manuale del prof. Pareto." Giornale degli Economisti [2], 32 (April), 296-301. English translation, "Mathematical Economics and Professor Pareto's New Manual." In Chipman, Hurwicz, Richter, and Sonnenschein (1971), 365-9.

Weber, C. E. (1999a) "Slutsky and Additive Utility Functions." History of Political Economy, 31 (Summer), 393-416.

Weber, C. E. (1999b) "Two Further Empirical Implications of Auspitz-LiebenEdgeworth-Pareto Complementarity." Unpublished manuscript.

Wilson, E. B. (1911) Advanced Calculus. New York: Ginn and Company.

Wold, H. O. A. (1943-44) "A Synthesis of Pure Demand Analysis. I, II, III," Skandinavisk Aktuarietidskrift, 26 (1943), 85-118, 220-263; 27 (1944), 69-120.

Wold, H. (1948) "On Giffen's Paradox.” Nordisk tidsskrift for teknisk фkonomi, 12, 283290.

Wold, H. (1953) Demand Analysis. New York: John Wiley \& Sons, Inc., and Stockholm: Almqvist \& Wiksell. 